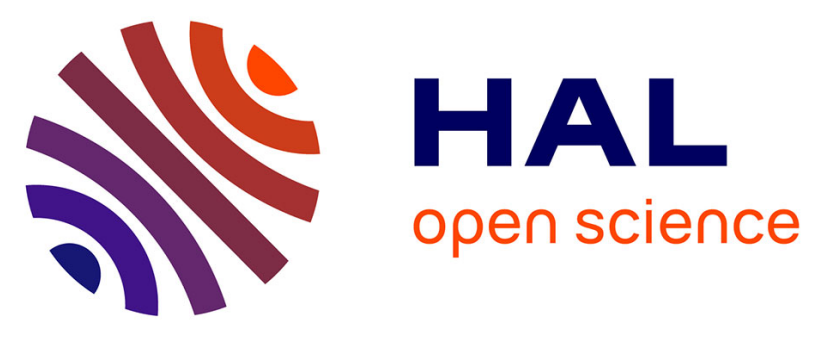

\title{
"Are you in full possession of your capacity?". A mechanistic self-control approach at trait and state levels to predict different health behaviors
}

Cyril Forestier, Philippe Sarrazin, Benoit Allenet, Aurélie Gauchet, Jean-Philippe Heuzé, Aïna Chalabaev

\section{To cite this version:}

Cyril Forestier, Philippe Sarrazin, Benoit Allenet, Aurélie Gauchet, Jean-Philippe Heuzé, et al.. "Are you in full possession of your capacity?". A mechanistic self-control approach at trait and state levels to predict different health behaviors. Personality and Individual Differences, 2018, 134, pp.214-221. 10.1016/j.paid.2018.05.044 . hal-01951342

\section{HAL Id: hal-01951342 \\ https://hal.science/hal-01951342}

Submitted on 11 Dec 2018

HAL is a multi-disciplinary open access archive for the deposit and dissemination of scientific research documents, whether they are published or not. The documents may come from teaching and research institutions in France or abroad, or from public or private research centers.
L'archive ouverte pluridisciplinaire HAL, est destinée au dépôt et à la diffusion de documents scientifiques de niveau recherche, publiés ou non, émanant des établissements d'enseignement et de recherche français ou étrangers, des laboratoires publics ou privés. 
“Are you in full possession of your capacity?". A mechanistic self-control approach at trait and state levels to predict different health behaviors

Cyril Forestier ${ }^{\mathrm{a}}$, Philippe Sarrazin ${ }^{\mathrm{a}}$, Benoît Allenet ${ }^{\mathrm{b}}$, Aurélie Gauchet ${ }^{\mathrm{c}}$, Jean-Philippe Heuzé ${ }^{\mathrm{a}}$, Aïna Chalabaev ${ }^{\mathrm{a}}$

${ }^{a}$ SENS, Univ. Grenoble Alpes, Grenoble F-38000, France, ${ }^{b}$ TIMC-IMAG, Univ. Grenoble Alpes, Grenoble F-38000, France, ${ }^{c} L I P-P C 2 S$, Univ. Grenoble Alpes, Grenoble F-38000, France.

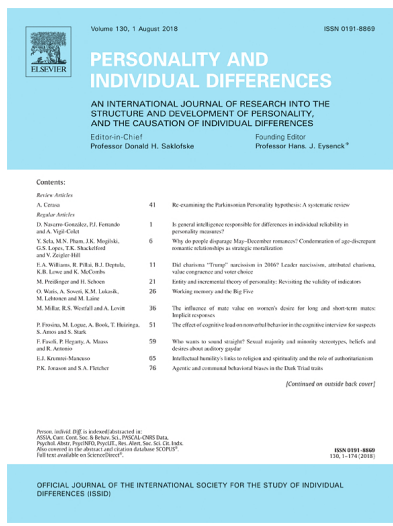

Accepted Manuscript

Personality and Individual Differences

\begin{abstract}
Author Note
Correspondence concerning this article should be addressed to Cyril Forestier or Aïna Chalabaev, Univ. Grenoble Alpes, SENS, F-38000; phone +33 (0)4 766350 81. This research was supported by a 'Alpes Grenoble Innovation Recherche' funding from Univ. Grenoble Alpes (grant number G7H-AG16BC86).
\end{abstract}

Declarations of interest: none 


\begin{abstract}
This study investigated the role of self-control in health behaviors at both trait and state levels. We examined if trait and state self-control independently predict health behaviors, as well as the mechanisms of these relationships (desire, conflict, and resistance). This question was investigated on unhealthy and healthy behaviors, in the domain of physical activity, diet, and smoking. 325 participants completed a questionnaire assessing trait and state self-control, as well as desire, conflict, resistance, and health behaviors. Path analyses revealed that trait self-control indirectly predicted unhealthy behaviors through reduced desire, conflict, and resistance, and directly predicted healthy behaviors. These relationships remained significant when controlling for state self-control, suggesting that people's general tendency to prioritize distal goals over proximal motives uniquely predicts behaviors. Results also showed that adding state self-control to the model doubled the explained variance in healthy behaviors, highlighting the importance of considering self-control capacity at both trait and state levels.

Keywords: Trait self-control capacity; state self-control capacity; self-control mechanisms; healthy behaviors; unhealthy behaviors.
\end{abstract}


“Are you in full possession of your capacity?". A mechanistic self-control approach at trait and state levels to predict different health behaviors

\section{Introduction}

Despite accumulating evidence that behaviors play a central role in health, most people have difficulties to adopt a healthy lifestyle (e.g., Ford, Zhao, Tsai, \& Li, 2011). Understanding the determinants of behavior change has thus become a hot topic in psychology, notably within socio-cognitive models (e.g., theory of planned behavior, Ajzen, 1991). Although these models have been successful in identifying key determinants of behavioral intention (e.g., self-efficacy, attitudes), intentions do not systematically translate into behavior change, a phenomenon known as the "intention-behavior gap". Self-control, which reflects the ability of the self to exert control over the self (Muraven \& Baumeister, 2000), represents a promising concept to address this limitation (e.g., Sniehotta, Presseau, \& Araujo-Soares, 2014). Indeed, individual differences in self-control have consistently been shown to predict health behaviors. For example, people with high self-control trait report less use of tobacco and less eating disorders than people with low self-control trait (for a review see de Ridder, Lensvelt-Mulders, Finkenauer, Stok, \& Baumeister, 2012).

However, the mechanisms through which self-control affects behaviors remain unclear. Traditionally, self-control is conceived as the ability to inhibit desires or habits (e.g., Hagger, Wood, Stiff, \& Chatzisarantis, 2010). The more people are able to resist desires that conflict with their long-term goals, the more likely self-control success is to occur (e.g., Kotabe \& Hofmann, 2015). Yet, recent research shows instead that high trait self-control is associated with reduced desire for problematic behaviors, reduced conflict between desires and long-term goals, and less 
resistance to conflict (e.g., Hofmann, Adriaanse, Vohs, \& Baumeister, 2014; Hofmann, Baumeister, Förster, \& Vohs, 2012; Luehring-Jones, Tahaney, \& Palfai, 2018). This is in line with a broader conceptualization of self-control as a general process by which people prioritize distal goals over proximal motives (Fujita, 2011). Here, effortful inhibition is one mechanism by which people control their behaviors, but more "proactive" strategies exist, such as avoiding temptations or developing healthy habits.

The goal of this study was to extend this line of research by investigating self-control at the dispositional and state levels. We examined if trait and state self-control independently predict health behaviors, as well as the mechanisms of these relationships (desire, conflict, and resistance). This questioning lies on evidence that although individual differences in self-control exist, this ability may also vary on a daily-life basis (e.g., Buyukcan-Tetik, Finkenauer, \& Bleidorn, (2018) and Hofmann et al., (2012). This suggests that people's available resources at a particular point in time may differ from the resources they have most of the time. If this is the case, are self-regulation behaviors affected by both trait and state self-control, and to what extent? On the one hand, we can consider based on the strength model of self-control (e.g., Muraven \& Baumeister, 2000) that behaviors are primarily determined by current self-control resources. On the other hand, a recent study on well-being showed that both trait and state selfcontrol contributed to this outcome, and that trait self-control was more predictive than state selfcontrol (Buyukcan-Tetik et al., 2018). This suggests that these two aspects of self-control should both be considered.

We examined the role of trait and state self-control on different types of health behaviors (unhealthy and healthy). Most research assumes that self-control effects on unhealthy behavior (e.g., eating junk food) and healthy behaviors (e.g., eating healthy) rely on the same processes, 
but empirical evidence of this assumption is lacking (de Ridder et al., 2012). Yet, such evidence is necessary because these two types of behaviors differ in an important way. Indeed, unhealthy behaviors may be attractive in the short term and need therefore to be inhibited; healthy behaviors may instead be unattractive in the short term and need therefore to be actively initiated (e.g., de Boer, Van Hooft, \& Bakker, 2011). The literature on approach and avoidance motivation suggests the relevance of distinguishing these two types of behaviors (e.g., achievement goals theory, Elliot, 2005; regulatory focus theory, Higgins, 1998). For example, the regulatory focus theory considers that people may pursue different types of goals: they are promotion-oriented when they pursue desirable outcomes (e.g., gains), and prevention-oriented when they strive to avoid undesirable outcomes (e.g., losses). Importantly, these goals lead to different emotions, cognitions and behaviors (Higgins, 2018). This suggests that self-control mechanisms could differ according to the nature of the behavior.

In sum, the current study investigated the mechanisms through which both trait and state self-control predict unhealthy and healthy behaviors, from a broad self- theoretical perspective. This questioning was examined in the domains of diet (eating balanced food and avoiding eating unbalanced food), physical activity (being physically active and avoiding being sedentary), and smoking (avoiding smoking). We hypothesized that trait and state self-control would predict behaviors independently from one another (e.g., Buyukcan-Telik et al., 2018). We also hypothesized that the self-control - unhealthy behaviors relationships would be mediated by decreased desire for these behaviors, reduced conflict between desires and long-term goals, and less resistance to conflict (e.g., Hofmann, Baumeister, et al., 2012; Luehring-Jones et al., 2018). Figure 1 summarizes our hypotheses. 


\section{Material and methods}

\subsection{Participants and procedure}

College students from five French universities were contacted through mailing lists to participate in an online study examining the relationships between their personal beliefs and health behaviors. They were further informed that their participation was anonymous and that their responses would be kept confidential. Sample size was determined before any data analysis, following Boomsma's (1985) recommendation to include a minimum of 200 participants when conducting structural equation modeling (we did not continue to collect data after data analysis). After having confirmed their consent to participate in this study, a sample of 422 voluntary individuals completed the online questionnaire (hosted on SurveyMonkey). The study was conducted in accordance with APA ethical principles in the conduct of research with human participants.

Seventy-nine participants were not considered in further analyses because they completed only the first page of the questionnaire (less than $15 \%$ of the items). In addition, data beyond three standard deviations from the mean of the variables of interest were removed, resulting in exclusion of eighteen more participants. The final sample was composed of 325 participants (188 women; $M_{\text {age }}=20.90, S D_{\text {age }}=4.62$ ). All measures, manipulations, and exclusions in the studies are disclosed.

\subsection{Measures}

\subsubsection{Trait self-control capacity.}

The Brief Self-Control Scale (BSCS) (Tangney, Baumeister, \& Boone, 2004) is a largely used scale to assess trait self-control. The BSCS is composed of 13 items (e.g., "I am good at resisting temptations", "I have a hard time breaking bad habits"). Participants responded on a 
seven-item Likert scale ranging from 1 (Completely disagree) to 7 (Completely agree). The scale presented good reliability in the present study $(\alpha=.77)$.

\subsubsection{State self-control capacity.}

State self-control was indexed by subjective vitality. This operationalization was chosen because subjective vitality corresponds closely to the definition of self-control capacity as one's perception of the mental resources or energy available to the self (Clarkson, Otto, Hassey, \& Hirt, 2016). Indeed, subjective vitality is defined as the energy available to the self (Ryan \& Deci, 2008). This construct may not be reduced to energy because other energy-related constructs such as anger, anxiety, or arousal, are unrelated or negatively related to it (Ryan \& Frederick, 1997). Instead, subjective vitality represents energy that one can harness or regulate for purposive actions (Ryan \& Deci, 2008), and is therefore similar to the definition of selfcontrol capacity.

In support to this idea, past research within the ego depletion literature has shown that exerting self-control can reduce subjective vitality (e.g., Hagger et al., 2010; Muraven, Gagné, \& Rosman, 2008; Rouse, Ntoumanis, \& Duda, 2013). For instance, Muraven et al. (2008) observed that decreased self-control performance after a depleting task was mediated by decreased subjective vitality. This suggests that subjective vitality and behavioral assessments of ego depletion tap into the same resources, with subjective vitality having the advantage of being a highly accessible, phenomenologically based variable (Ryan \& Deci, 2008).

More particularly, participants completed the Subjective Vitality Scale (Ryan \& Frederick, 1997). This scale began with the stem: "Indicate to what extent each of the following sentence reflects the general feelings you had during the past two days". It was composed of five items (e.g. "I felt alive and vital") and responses ranged on a seven-item Likert scale from 1 
(Completely disagree) to 7 (Completely agree). The scale presented good reliability $(\alpha=.70)$.

Past research showed that this measure may fluctuate over time (e.g., Emile, d'Arripe-

Longueville, Cheval, Amato, \& Chalabaev, 2015; Smolders, de Kort, \& van den Berg, 2013). For example, Smolders et al. (2013) observed that more than $65 \%$ of the variance in feelings of vitality occurred within individuals, at the level of time of day. This suggests that this measure may be appropriate to capture state of self-control capacity.

\subsubsection{Self-control mechanisms.}

Desire, desire-intention conflict, and resistance were assessed with the items used in (Hofmann et al., 2012). Items were preceded by the stem: "Among the following behaviors, what are those you have desired doing and to what extent, during the past two days?". The stem was followed by five items focusing on the three unhealthy behaviors of interest (i.e., sedentary activity, unhealthy diet, tobacco consumption). More particularly, desire frequency and strength ${ }^{1}$ were measured by the items: "With which frequency have you experienced a desire for sedentary activities?", and "How strong was the desire for sedentary activities?" (words in italic differed depending on the target behavior). Participants responded on a 8-item scale ranging from 0 (No desire at all) to 7 (Irresistible desire). Desire-intention conflict was measured by the item: "To what extent did this desire conflict with your intention to avoid sedentary activities?". Participants responded on a 8-item scale ranging from 0 (No conflict at all) to 7 (Very high conflict). Finally, resistance (i.e., self-control effort) was assessed with the item: "To what extent

\footnotetext{
${ }^{1}$ Given that results were similar for desire strength and desire frequency, we present here only results for
} desire strength, following Hofmann, Baumeister, et al. (2012). 
have you attempted to resist the desire for sedentary activities?". Participants responded on a 8item scale ranging from 0 (No resistance at all) to 7 (Very high resistance).

\subsubsection{Health behaviors.}

Physical and sedentary activities were measured with the French version of the International Physical Activity Questionnaire (Craig et al., 2003), which assesses moderate and vigorous physical activity. For each of these intensities, participants were asked to indicate the number of days during which they did at least 10 min sessions of physical activity, and how many minutes, during the last week. We then summed the scores on the moderate and vigorous physical activity items, to obtain the Moderate to Vigorous Physical Activity score (MVPA score). The IPAQ also assesses walking time in minutes during the last week, and sedentary time, defined as the time in minutes spent in a sitting position during the last week.

Healthy and unhealthy diet were measured with the Healthy Eating Behaviour Scale (Pelletier, Dion, Slovinec-D’Angelo, \& Reid, 2004). This 8-item scale is composed of two subscales assessing diet behavior during the last week. Four items measure healthy diet: "I eat vegetables, fruits and grain products", "I eat a variety of foods which balance the four alimentary groups (fruits and vegetables, dairy products, starches, meat/fish/eggs)", "I eat foods that are low in fat, saturated fat, and cholesterol", and "I drink water". The other four items measure unhealthy diet: "I eat food such as chips, chocolate, and candies", "I eat fried food", "I use white sugar", and "I use salt". Participants indicated their consumption frequency on a seven-item scale ranging from 1 (Once or twice per month) to 7 (More than three times per day). In contrast to Pelletier et al. (2004), who averaged the items of each subscale, we decided instead to sum the responses of each subscale to obtain the Healthy Diet Score (ranging from 4 to 28) and the Unhealthy Diet Score (ranging from 4 to 28). Indeed, following (Steca et al., 2015)'s reasoning, 
we considered that eating one particular type of unhealthy food (e.g., white sugar) may be unrelated to the consumption of other types of unhealthy food (e.g., fried food). It seems therefore conceptually irrelevant to aggregate items that may be independent from each other. A sum may instead better quantify the consumption of unhealthy or healthy food. Finally, tobacco consumption was measured with a single-item “How many cigarettes do you smoke per week?".

\section{Results}

\subsection{Preliminary analyses}

All data is available upon request to the first author. We checked that variables were normally distributed by examining their skewness and kurtosis. Distribution of all variables were normal, except MVPA score, sedentary time, and number of cigarettes smoked. A square root transformation was therefore applied to these variables. Means, standard deviations, and Cronbach's alpha coefficients are presented in the supplementary materials, as well as Pearson correlations between the variables of interest. Results showed that MVPA was not significantly related to sedentary time, $r(324)=-.03, p=.62$, and unhealthy diet was not significantly correlated with healthy diet, $r(324)=.01, p=.89$. This indicates that healthy and unhealthy behaviors within the same domain are independent from one another.

\subsection{Primary analyses}

\subsubsection{Analytic strategy.}

We ran path analyses to test our predictions using AMOS 23.0 with maximum likelihood estimation. The same path analytic models were tested for each behavior domain (physical activity, diet, and smoking). The baseline model included all variables (i.e., trait self-control capacity, desire, conflict, and resistance) except state self-control, which was added in the final model. This two-step method allowed us to examine whether state self-control added explained 
variance in health behaviors. Chi-square differences tests of the baseline versus final models were also conducted to evaluate if these increases in explained variance were significant.

The models' fit was assessed by examining the minimum discrepancy (CMIN/DF), the probability level (p-value), the Bentler-Bonett normed fit index (NFI), the comparative fit index (CFI), the Tucker-Lewis-Index (TLI), and the root-mean-square error of approximation (RMSEA). A satisfactory model fit is indicated by a CMIN/DF ratio below 2.00 (Byrne, 2012), a p-value over .05 (Arbuckle \& Wothke, 2001), a NFI over .95 (Schumacker \& Lomax, 2004), a TLI over .90 (Tabachnick \& Fidell, 2001), a CFI over .93 (Byrne, 1994), and a RMSEA below .05 (Stieger et al., 1990). All non-significant paths were deleted according to the methods described by (MacCallum, 1986).

In addition, the cross-sectional nature of the design prevents from drawing causal inferences. We therefore tested for each behavior a reverse model in which behavior was the predictor and self-control capacity the outcome, in order to rule out the alternative hypothesis that adopting health behaviors predicts self-control capacity. Indeed, given that health behaviors adoption is related to well-being (Cheng, Weiss \& Siegel, 2015), and that subjective vitality is a component of well-being (Ryan \& Frederick, 1997), one could predict the reverse relationships to the ones we predicted. Indices of these reverse models were not adequate, ruling out this alternative hypothesis $(\mathrm{CMIN} / \mathrm{DF}=4.00, p<.001, \mathrm{NFI}=.72, \mathrm{TLI}=.41, \mathrm{CFI}=.75, \mathrm{RMSEA}$ $=.10$, for the physical and sedentary activity model; $\mathrm{CMIN} / \mathrm{DF}=3.24, p=.00, \mathrm{NFI}=.87$, TLI $=.78, \mathrm{CFI}=.90, \mathrm{RMSEA}=.08$, for the healthy and unhealthy diet model, and $\mathrm{CMIN} / \mathrm{DF}=$ $8.47, p=.00, \mathrm{NFI}=.87, \mathrm{TLI}=.73, \mathrm{CFI}=.88, \mathrm{RMSEA}=.15$ for the smoking model). 


\subsubsection{Path analyses.}

\subsubsection{Self-control components predicting physical and sedentary activity.}

Results of the baseline and final models are presented in Figure 2. Both models provided good fit to the data $(\mathrm{CMIN} / \mathrm{DF}=1.49, \mathrm{p}=.16, \mathrm{NFI}=.90, \mathrm{TLI}=.89, \mathrm{CFI}=.96, \mathrm{RMSEA}=.04$, for the baseline model; CMIN/DF $=1.07, \mathrm{p}=.38, \mathrm{NFI}=.93, \mathrm{TLI}=.99, \mathrm{CFI}=.99, \mathrm{RMSEA}$ $=.02$, for the final model). Desire positively predicted conflict, which positively predicted resistance, which in turn negatively predicted sedentary activity. In other words, the more participants reported a strong desire for sedentary activity, the more they experienced conflict between this desire and their intention to be physically active, and the more they resisted this desire; in turn, the more they resisted it, the less they spent time being sedentary. A direct positive relationship between desire and sedentary activity was also observed. Results concerning self-control capacity showed that both trait and state self-control negatively predicted desire for sedentary activity. Additional results showed that state self-control directly and positively predicted physical activity, and that trait self-control negatively predicted conflict.

Finally, inclusion of state self-control added explained variance in physical activity, which increased from $\mathrm{R}^{2}=.03$ to $\mathrm{R}^{2}=.07$. However, the chi-square difference test revealed that the final model did not significantly differ from the baseline model $\left(\Delta \chi^{2}=.91, \Delta \mathrm{df}=4, p>.05\right)$.

[Insert Figure 2 here]

\subsubsection{Self-control components predicting healthy and unhealthy diet.}

Results of the baseline and final models are presented in Figure 3. Both models provided good fit to the data $(\mathrm{CMIN} / \mathrm{DF}=1.05, p=.39, \mathrm{NFI}=.96, \mathrm{TLI}=.99, \mathrm{CFI}=.96, \mathrm{RMSEA}=.01$, for the baseline model; $\mathrm{CMIN} / \mathrm{DF}=1.58, p=.08, \mathrm{NFI}=.93, \mathrm{TLI}=.94, \mathrm{CFI}=.97, \mathrm{RMSEA}$ $=.04$, for the final model). Again, desire positively predicted conflict, which positively predicted 
resistance. In other words, the more participants reported a strong desire for unhealthy food, the more they experienced conflict between this desire and their intention to eat healthy, and the more they resisted this desire. However, resistance did not significantly predict unhealthy food consumption. A direct positive relationship between desire and unhealthy food consumption was nevertheless observed. Results concerning self-control capacity showed that both trait and state self-control directly and positively predicted consumption of healthy food, while trait self-control also negatively predicted consumption of unhealthy food. Moreover, inclusion of state selfcontrol added explained variance in healthy food consumption, which increased from $\mathrm{R}^{2}=.08$ to $\mathrm{R}^{2}=.13$. Finally, the chi-square difference test showed that the final model significantly differed from the baseline model $\left(\Delta \chi^{2}=11.05, \Delta \mathrm{df}=4, p<.05\right)$.

[Insert Figure 3 here]

\subsubsection{Self-control components predicting smoking.}

Results of the baseline and final models are presented in Figure 4. The final model provided better fit to the data $(\mathrm{CMIN} / \mathrm{DF}=3.66, p=.00, \mathrm{NFI}=.97, \mathrm{TLI}=.93, \mathrm{CFI}=.98$, $\mathrm{RMSEA}=.09$, for the baseline model; $\mathrm{CMIN} / \mathrm{DF}=2.78, p=.01, \mathrm{NFI}=.96, \mathrm{TLI}=.98, \mathrm{CFI}$ $=.98, \mathrm{RMSEA}=.07$, for the final model). Similar to physical activity behaviors, desire positively predicted conflict, which positively predicted resistance, which in turn negatively predicted cigarette consumption. In other words, the more participants reported a strong desire for smoking, the more they experienced conflict between this desire and their intention not to smoke, and the more they resisted this desire; in turn, the more they resisted it, the less they smoked. A direct positive relationship between desire and smoking was also observed. Results concerning self-control capacity showed that neither trait nor state self-control directly predicted smoking. However, trait self-control negatively predicted desire while state self-control 
negatively predicted conflict. Finally, inclusion of state self-control did not explain more variance in cigarette consumption. This observation was confirmed by the chi-square difference test, which indicated that the final model did not significantly differ from the baseline model $\left(\Delta \chi^{2}\right.$ $=3.78, \Delta \mathrm{df}=3, p>.05)$.

[Insert Figure 4 here]

\section{Discussion}

\section{Role of trait self-control capacity}

When considering self-control at the trait level only, results were in line with recent research (Hofmann et al., 2014; Hofmann, Baumeister, et al., 2012; Luehring-Jones, et al., 2018): the more individuals had high trait self-control, the less they experienced desires for unhealthy behaviors (sedentary activities, unhealthy food, and smoking). In turn, less desire was generally associated with less conflict, less resistance, and less behavior enactment. Interestingly, results showed that trait self-control affected both unhealthy and healthy behaviors, whereas these behaviors differ in an important way: the former need to be inhibited and the latter need to be initiated. Taken together, these findings are in line with a broad conceptualization of self-control, in which inhibition represents only one manner to control behavior among other manners (e.g., avoiding temptations, developing healthy habits) (e.g., de Ridder et al., 2011; Fujita, 2011; Galla \& Duckworth, 2015).

This interpretation was reinforced by the result that trait self-control still predicted behaviors when controlling for state self-control (except physical activity). This indicates that people's current available resources are not sufficient to explain self-control success or failure, and that their general tendency to prioritize distal goals over proximal motives uniquely predicts behaviors. This result corroborates the idea that high trait self-controllers use self-control 
strategies that enable them to be successful in different situations and extended periods of time, and notably effortless strategies (e.g., avoiding temptations) (e.g., Gillebaart \& de Ridder, 2015).

\section{Role of state self-control capacity}

Concerning state self-control, its role was more manifest with regard to healthy

behaviors. Indeed, including state self-control to the baseline model doubled the explained variance in physical activity and healthy diet. This suggests that such behaviors may more particularly necessitate available self-control resources or energy available to the self, in order to be actively initiated. However, this increase in explained variance was significant for diet but not for physical activity, which could be due to the low level of explained variance for the physical activity model. This suggests that the role of state self-control capacity differ according to the behavior domain. In addition, these findings corroborate the idea that self-control mechanisms may differ for healthy and unhealthy behaviors. This is in line with the literature on approach and avoidance motivation, which shows that pursuing something desirable and striving to avoid something undesirable are associated with different psychological and behavioral outcomes (e.g., Higgins, 1998).

In sum, this study shows the relevance of considering self-control capacity both at the trait and state levels. While research on these two facets has developed separately, our results showed that they both predicted behavior independently from each other. Taking into account these two aspects of self-control may therefore be useful to better understand the role of selfcontrol in health behaviors (e.g., Buyukcan-Tetik et al., 2018). Overall, our findings raise the question of what processes drive the direct relationships between self-control capacity and healthy behaviors. 


\section{Self-control mechanisms are behavior-dependent}

Finally, some differences were observed in self-control processes depending on behaviors. While desire directly predicted all unhealthy behaviors, this relationship was much stronger for smoking than for sedentary activity and unhealthy diet. This may be explained by the fact that smoking is addictive, and therefore particularly susceptible to desire strength. In addition, resistance was found to significantly predict sedentary activity and smoking, but not unhealthy diet. These findings suggest that the causes of self-control failures may differ according to the behavior domain, with desire playing a major role especially in smoking. This is in line with the idea that theories that are applicable to one particular behavior may not be applicable to another one, and that identifying the underlying processes of health behaviors requires to accurately define the target behavior (Michie, Johnston, Abraham, Lawton, Parker, \& Walker, 2005). This reasoning is further reinforced by the differences observed in the variance in behaviors explained by the final models $(69 \%$ in cigarette consumption, $13 \%$ in healthy diet, $8 \%$ in unhealthy diet, $7 \%$ in physical activity, and 3\% in sedentary activity). Finally, results for the physical activity model showed a direct relationship between trait self-control and conflict after controlling for desire. This suggests that high self-controllers use other strategies than temptation avoidance, for example, they may be better able to draw their attention away from the problematic desire (e.g., when they are tempted by a sedentary behavior, they may focus on another activity, reducing in turn the experienced conflict).

\section{Limits and future directions}

This study is not without limitations, notably due to the cross-sectional nature of the design, which presents limits that are specific to the study of psychological states fluctuating over time. Indeed, even if participants were asked to rate their subjective vitality within a short 
time frame (two days), there was only one measurement occasion and fluctuations were not assessed. Although this study represents an initial step in the identification of the distinctive role of trait and state of self-control capacity, future studies should adopt a longitudinal methodology such as experience sampling method (e.g., Hofmann et al., 2012), or rely on a latent state-trait approach (Steyer et al., 1999), which is particularly relevant to assess and distinguish precisely states variations from trait of a psychological construct.

Another promising avenue of research would be to articulate research on self-control with socio-cognitive models of behavior change, such as the Health Action Process Approach (Schwarzer, 2008). This model identifies action planning (defining when, where, and how to act) and coping planning (defining strategies to prioritize long-term goals over habitual responses when obstacles are faced) as key self-regulatory mechanisms to translate health goals into action. These strategies appear as likely candidates to explain the self-control capacity - behavior relationship, and future research should examine this possibility.

\section{Conclusion}

Results highlight that self-control mechanisms differ according to the health behavior considered, and suggest the importance of distinguishing trait from state self-control capacity in these mechanisms. Future research may help to better understand these processes by articulating them with more traditional socio-cognitive models of behavior change, and by adopting a longitudinal design such as the experience sampling method. 


\section{References}

Ajzen, I. (1991). The theory of planned behavior. Organizational Behaviour and Human Decision Processes, 50(2), 179-211. http://dx.doi.org/10.1016/0749-5978(91)90020-t

Arbuckle, J., \& Wothke, W. (2011) Structural equation modeling using AMOS: An Introduction [EB].

Boomsma, A. (1985). Nonconvergence, improper solutions, and starting values in Lisrel maximum likelihood estimation. Psychometrika, 50(2), 229-242. http://dx.doi.org/10.1007/bf02294248

Buyukcan-Tetik, A., Finkenauer, C., \& Bleidorn, W. (2018). Within-person variations and between-person differences in self-control and wellbeing. Personality and Individual Differences, 122, 72-78. http://dx.doi.org/10.1016/j.paid.2017.10.013

Byrne, B. M. (1994). Structural equation modeling with EQS and EQS/Windows: Basic concepts, applications, and programming. (1994). Applied Psychological Measurement, 18(2), 191-194. http://dx.doi.org/10.1177/014662169401800208

Byrne, B. (1989). A primer of LISREL: Basic applications and programming for confirmatory factor analytic models. New York: Springer Verlag.

Clarkson, J. J., Otto, A. S., Hassey, R., \& Hirt, E. R. (2016). Perceived mental fatigue and selfcontrol. Self-Regulation and Ego Control, 185.

Cheng, C., Weiss, J., \& Siegel, J. (2015). Personality traits and health behaviors as predictors of subjective wellbeing among a multiethnic sample of university-attending emerging young adults. International Journal of Wellbeing, 5(3), 21-43. http://dx.doi.org/10.5502/ijw.v5i3.2

Craig, C. L., Marshall, A. L., Sjostrom, M., Bauman, A. E., Booth, M. L., Ainsworth, B. E., et al. (2003). International physical activity questionnaire: 12-country reliability and validity. Medicine and Science in Sports and Exercise, 35(8), 1381-1395. http://dx.doi.org/10.1249/01.mss.0000078924.61453.fb

de Boer, B., van Hooft, E., \& Bakker, A. (2011). Stop and start control: A distinction within selfcontrol. European Journal of Personality, 25(5), 349-362. http://dx.doi.org/10.1002/per.796

de Ridder, D., de Boer, B., Lugtig, P., Bakker, A., \& van Hooft, E. (2011). Not doing bad things is not equivalent to doing the right thing: Distinguishing between inhibitory and initiatory 
self-control. Personality and Individual Differences, 50(7), 1006-1011. http://dx.doi.org/10.1016/j.paid.2011.01.015

de Ridder, D., Lensvelt-Mulders, G., Finkenauer, C., Stok, F., \& Baumeister, R. (2012). Taking stock of self-control. Personality and Social Psychology Review, 16(1), 76-99. http://dx.doi.org/10.1177/1088868311418749

Elliot, A. J. (2005). A conceptual history of the achievement goal construct. In A. Elliot \& C. Dweck (Eds.), Handbook of competence and motivation (pp. 52-72). New York: Guilford Press.

Emile, M., d'Arripe-Longueville, F., Cheval, B., Amato, M., \& Chalabaev, A. (2014). An ego depletion account of aging stereotypes' effects on health-related variables. The Journals of Gerontology Series B: Psychological Sciences and Social Sciences, 70(6), 876-885. http://dx.doi.org/10.1093/geronb/gbu168

Ford, E., Zhao, G., Tsai, J., \& Li, C. (2011). Low-risk lifestyle behaviors and all-cause mortality: Findings from the National Health and Nutrition Examination Survey III mortality study. American Journal of Public Health, 101(10), 1922-1929. http://dx.doi.org/10.2105/ajph.2011.300167

Fujita, K. (2011). On conceptualizing self-control as more than the effortful inhibition of impulses. Personality and Social Psychology Review, 15(4), 352-366. http://dx.doi.org/10.1177/1088868311411165

Galla, B., \& Duckworth, A. (2015). More than resisting temptation: Beneficial habits mediate the relationship between self-control and positive life outcomes. Journal of Personality and Social Psychology, 109(3), 508-525. http://dx.doi.org/10.1037/pspp0000026

Gillebaart, M., \& Ridder, D. T. (2015). Effortless self-control: A novel perspective on response conflict strategies in trait self-control. Social and Personality Psychology Compass, 9(2), 88-99. doi:10.1111/spc3.12160

Hagger, M., Wood, C., Stiff, C., \& Chatzisarantis, N. (2010). Ego depletion and the strength model of self-control: A meta-analysis. Psychological Bulletin, 136(4), 495-525. http://dx.doi.org/10.1037/a0019486

Higgins, E. T. (1998). Promotion and prevention: Regulatory focus as a motivational principle. Advances in Experimental Social Psychology, 46, 1-46. doi:10.1016/s00652601(08)60381-0 
Hofmann, W., Adriaanse, M., Vohs, K., \& Baumeister, R. (2014). Dieting and the self-control of eating in everyday environments: An experience sampling study. British Journal of Health Psychology, 19(3), 523-539. http://dx.doi.org/10.1111/bjhp.12053

Hofmann, W., Baumeister, R., Förster, G., \& Vohs, K. (2012). Everyday temptations: An experience sampling study of desire, conflict, and self-control. Journal of Personality and Social Psychology, 102(6), 1318-1335. http://dx.doi.org/10.1037/a0026545

Hofmann, W., Vohs, K., \& Baumeister, R. (2012). What people desire, feel conflicted about, and try to resist in everyday life. Psychological Science, 23(6), 582-588. http://dx.doi.org/10.1177/0956797612437426

Kotabe, H., \& Hofmann, W. (2015). On integrating the components of self-control. Perspectives on Psychological Science, 10(5), 618-638. http://dx.doi.org/10.1177/1745691615593382

Luehring-Jones, P., Tahaney, K. \& Palfai, T. (2018). The effect of self-control on drinking outcomes is mediated by automatic appetitive responses to alcohol. Personality and Individual Differences, 125, 116-119.https://doi.org/10.1016/j.paid.2018.01.011

MacCallum, R. (1986). Specification searches in covariance structure modeling. Psychological Bulletin, 100(1), 107-120. http://dx.doi.org/10.1037/0033-2909.100.1.107

Michie, S., Johnston, M., Abraham, C., Lawton, R., Parker, D., \& Walker, A. (2005). Making psychological theory useful for implementing evidence based practice: A consensus approach. Quality and Safety in Health Care, 14(1), 26-33. http://dx.doi.org/10.1136/qshc.2004.011155

Muraven, M., \& Baumeister, R. (2000). Self-regulation and depletion of limited resources: Does self-control resemble a muscle?. Psychological Bulletin, 126(2), 247-259. http://dx.doi.org/10.1037//0033-2909.126.2.247

Muraven, M., Gagné, M., \& Rosman, H. (2008). Helpful self-control: Autonomy support, vitality, and depletion. Journal of Experimental Social Psychology, 44(3), 573-585. http://dx.doi.org/10.1016/j.jesp.2007.10.008

Pelletier, L., Dion, S., Slovinec-D'Angelo, M., \& Reid, R. (2004). Why do you regulate what you eat? Relationships between forms of regulation, eating behaviors, sustained dietary behavior change, and psychological adjustment. Motivation and Emotion, 28(3), 245-277. http://dx.doi.org/10.1023/b:moem.0000040154.40922.14 
Rouse, P., Ntoumanis, N., \& Duda, J. (2013). Effects of motivation and depletion on the ability to resist the temptation to avoid physical activity. International Journal of Sport and Exercise Psychology, 11(1), 39-56. http://dx.doi.org/10.1080/1612197x.2012.717779

Ryan, R., \& Deci, E. (2008). From ego depletion to vitality: Theory and findings concerning the facilitation of energy available to the self. Social and Personality Psychology Compass, 2(2), 702-717. http://dx.doi.org/10.1111/j.1751-9004.2008.00098.x

Ryan, R., \& Frederick, C. (1997). On energy, personality, and health: Subjective vitality as a dynamic reflection of well-being. Journal of Personality, 65(3), 529-565. http://dx.doi.org/10.1111/j.1467-6494.1997.tb00326.x

Schumacker, R., \& Lomax, R. (2004). A Beginner's guide to structural equation modeling. Mahwah (New Jersey): L. Erlbaum Associates.

Schwarzer, R. (2008). Modeling health behavior change: How to predict and modify the adoption and maintenance of health behaviors. Applied Psychology, 57(1), 1-29. http://dx.doi.org/10.1111/j.1464-0597.2007.00325.x

Smolders, K. C. H. J., de Kort, Y. A. W., \& van den Berg, S. M. (2013). Daytime light exposure and feelings of vitality: Results of a field study during regular weekdays. Journal of Environmental Psychology, 36, 270-279. doi:10.1016/j.jenvp.2013.09.004

Sniehotta, F., Presseau, J., \& Araújo-Soares, V. (2014). Time to retire the theory of planned behavior. Health Psychology Review, 8(1), 1-7. http://dx.doi.org/10.1080/17437199.2013.869710

Steca, P., Pancani, L., Greco, A., D'Addario, M., Magrin, M., \& Miglioretti, M. et al. (2015). Changes in dietary behavior among coronary and hypertensive patients: A longitudinal investigation Using the Health Action Process Approach. Applied Psychology: Health and Well-Being, 7(3), 316-339. http://dx.doi.org/10.1111/aphw.12050

Steiger, J. (1990). Structural model evaluation and modification: An interval estimation approach. Multivariate Behavioural Research, 25(2), 173-180. http://dx.doi.org/10.1207/s15327906mbr2502_4

Tabachnick, B. G., Fidell, L. S., \& Osterlind, S. J. (2001). Using multivariate statistics. Boston: Allyn and Bacon 
Tangney, J., Baumeister, R., \& Boone, A. (2004). High self-control predicts good adjustment, less pathology, better grades, and interpersonal success. Journal of Personality, 72(2), 271-324. http://dx.doi.org/10.1111/j.0022-3506.2004.00263.x 
Acknowledgments

Authors wish to express their gratitude to University Grenoble Alpes for their funding.

\section{“ARE YOU IN FULL POSSESSION OF YOUR CAPACITY?”}

(1)


Figure 1. Hypothetical model of self-control correlates of unhealthy and healthy behaviors

Figure 2. Physical and sedentary activity baseline model (without state self-control capacity) and final model (with state self-control capacity). All coefficients are unstandardized. $t$ represents $\mathrm{p}<.10, * \mathrm{p}<.05, * * \mathrm{p}<.01, * * * \mathrm{p}<.001$

Figure 3. Healthy and unhealthy diet baseline model (without state self-control capacity) and final model (with state self-control capacity). All coefficients are unstandardized. $t$ represents $\mathrm{p}<.10, * \mathrm{p}<.05, * * \mathrm{p}<.01, * * * \mathrm{p}<.001$

Figure 4. Tobacco consumption baseline model (without state self-control capacity) and final model (with state self-control capacity). All coefficients are unstandardized. t represents $\mathrm{p}<$ $.10, * \mathrm{p}<.05, * * \mathrm{p}<.01, * * * \mathrm{p}<.001$ 


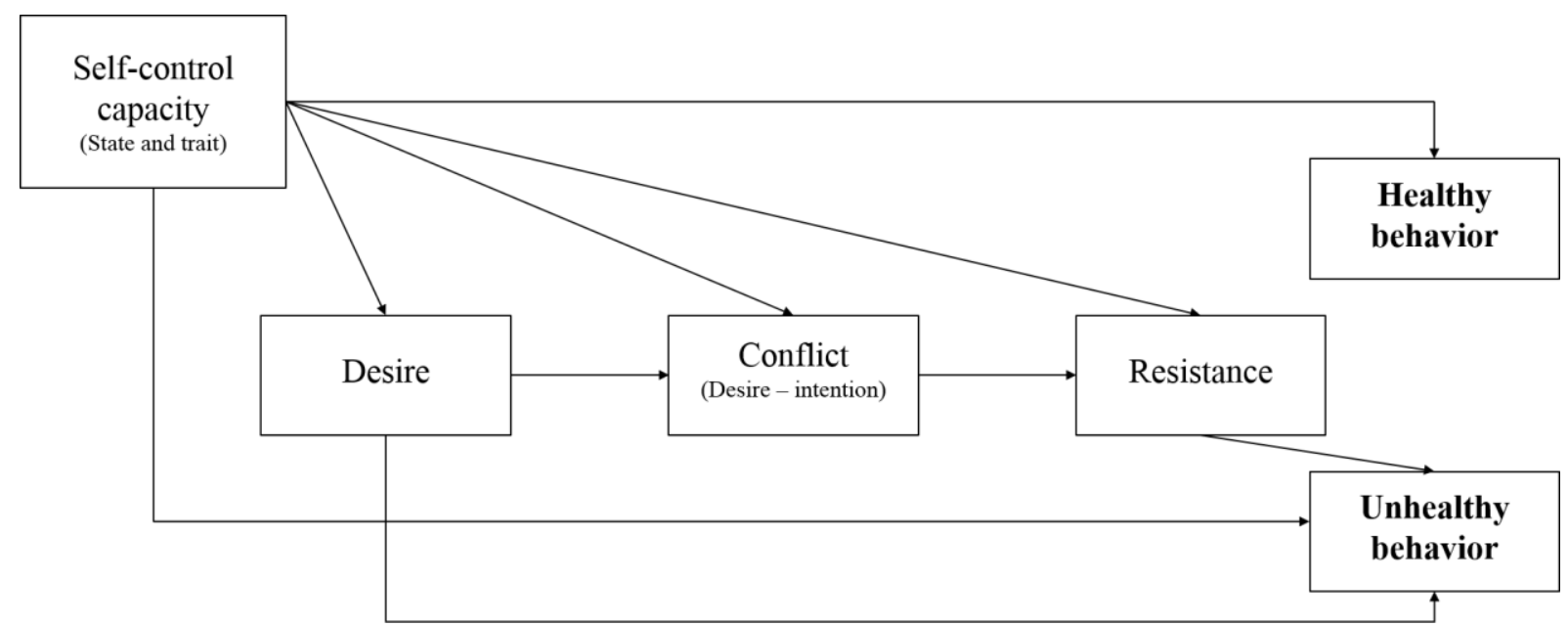

Figure 1. 


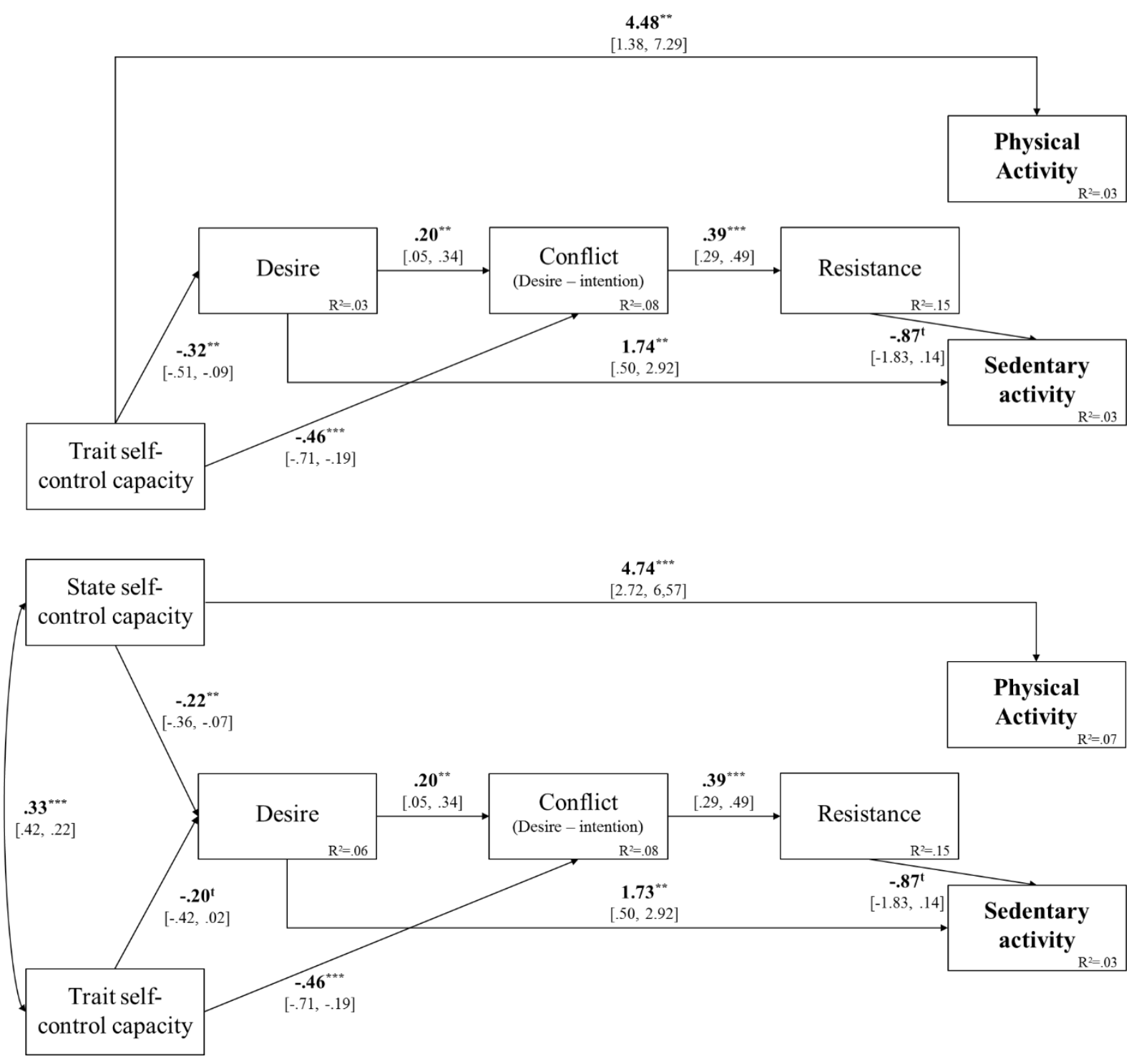

Figure 2. 


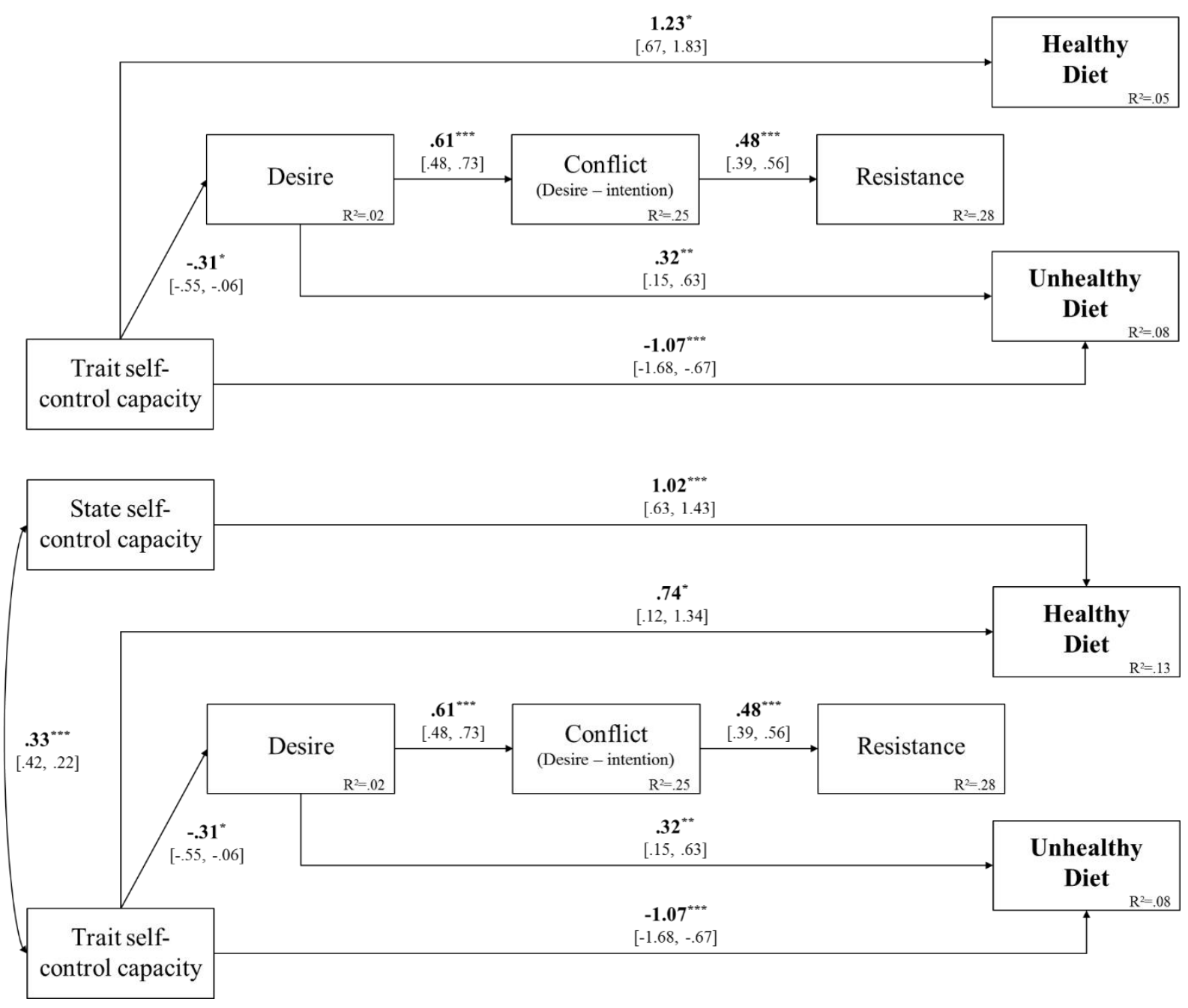

Figure 3. 


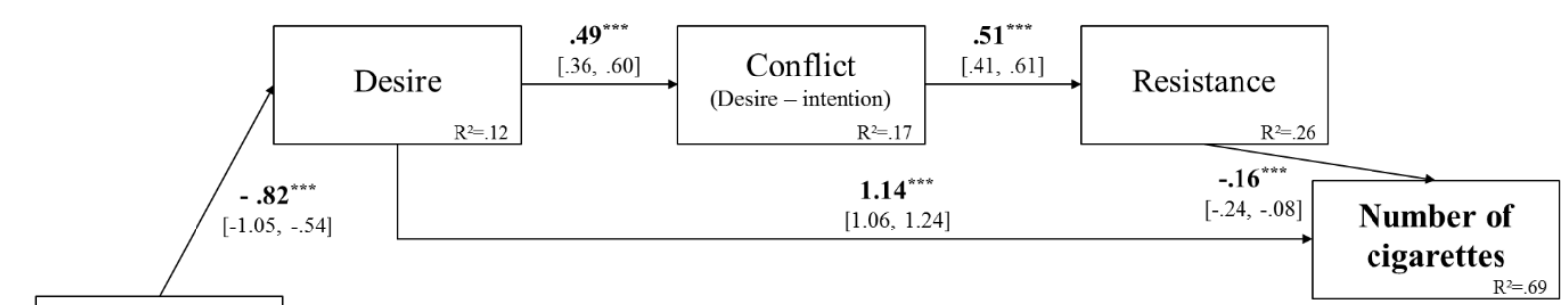

Trait selfcontrol capacity

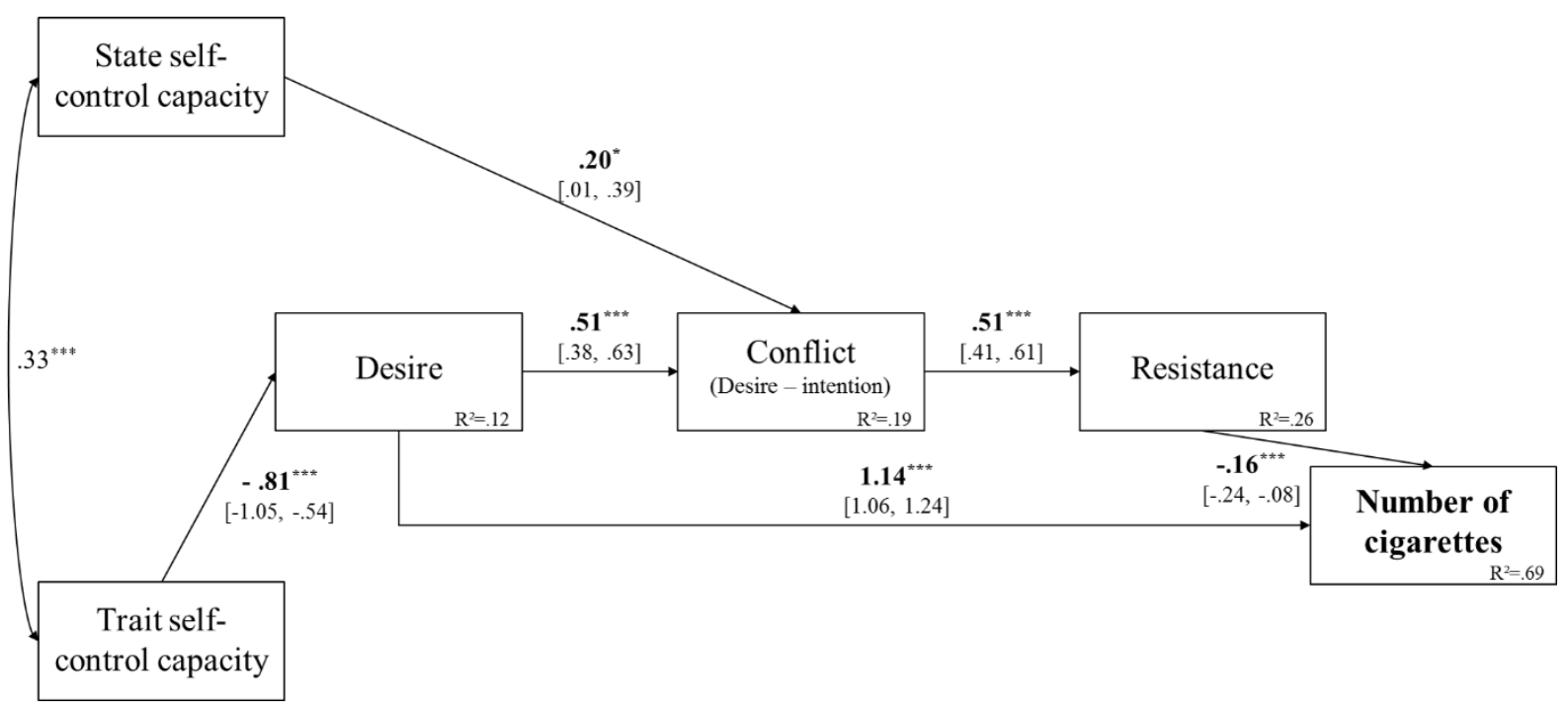

Figure 4. 
Table 1

Means, Standard Deviations and Cronbach's Alpha Coefficient

\begin{tabular}{|c|c|c|c|c|}
\hline $\begin{array}{l}\text { Variable } \\
\text { category }\end{array}$ & Variable name & $M$ & $S D$ & Alpha \\
\hline \multicolumn{5}{|l|}{$\begin{array}{l}\text { Unspecific } \\
\text { variables }\end{array}$} \\
\hline & Trait self-control capacity & 4.24 & 0.85 & .76 \\
\hline & State self-control capacity & 4.14 & 1.31 & .85 \\
\hline \multicolumn{5}{|c|}{$\begin{array}{l}\text { Physical activity } \\
\text { variables }\end{array}$} \\
\hline & Desire & 4.15 & 1.62 & \\
\hline & Conflict (desire - intention) & 3.27 & 1.98 & \\
\hline & Resistance & 3.06 & 1.95 & \\
\hline & MVPA score & 1850 & 2093 & \\
\hline & Sedentary time & 1448 & 1234 & \\
\hline \multicolumn{5}{|c|}{$\begin{array}{l}\text { Alimentation } \\
\text { variables }\end{array}$} \\
\hline & Desire & 4.35 & 1.88 & \\
\hline & Conflict (desire - intention) & 3.83 & 2.30 & \\
\hline & Resistance & 3.65 & 2.06 & \\
\hline & Healthy food score & 20.18 & 4.60 & \\
\hline & Unhealthy food score & 11.51 & 4.03 & \\
\hline \multicolumn{5}{|l|}{$\begin{array}{c}\text { Tobacco } \\
\text { variables }\end{array}$} \\
\hline & Desire & 2.25 & 2.01 & \\
\hline & Conflict (desire - intention) & 2.44 & 2.34 & \\
\hline & Resistance & 2.53 & 2.33 & \\
\hline & Number of cigarettes & 9.27 & 22 & \\
\hline
\end{tabular}


Table 2.

Pearson correlations between the variables of interest

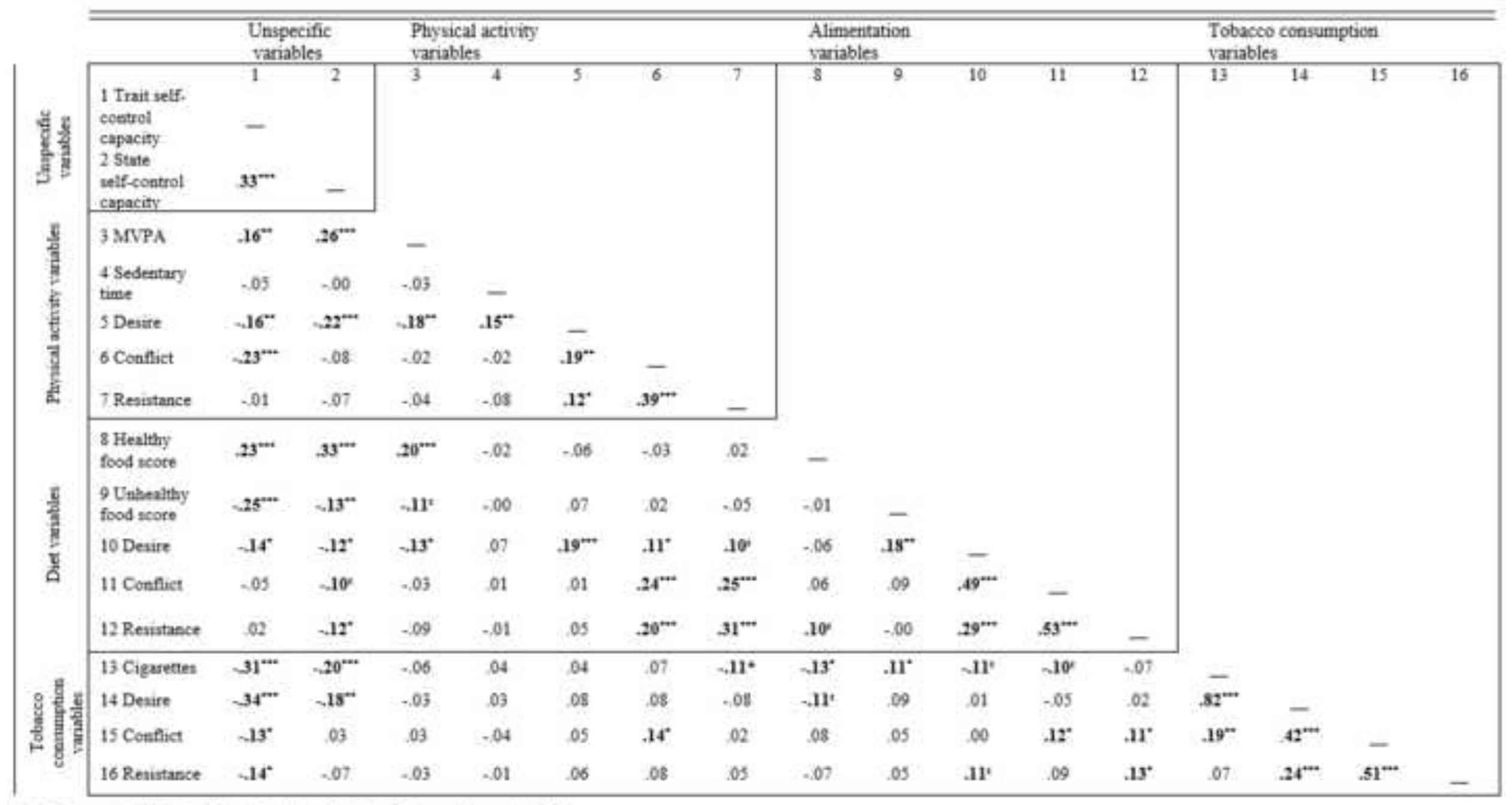

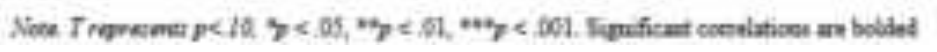




\section{Supplementary Material}

Click here to download Supplementary Material: Supplementary materials n3 Indirect and total effects.docx

Table 1. Physical and sedentary activity models. All coefficients are unstandardized. Significant coefficients are bolded. * $\mathrm{p}<.05, * * \mathrm{p}<.01, * * * \mathrm{p}<.001$. Numbers into brackets represent $95 \%$ confidence intervals.

\begin{tabular}{|c|c|c|c|c|c|c|c|c|c|c|c|c|}
\hline & & & & & ect effect & & & & & otal effec & & \\
\hline & & 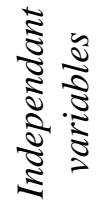 & $\begin{array}{c}\text { State self } \\
\text { control capacity }\end{array}$ & $\begin{array}{l}\text { Trait self } \\
\text { control } \\
\text { capacity }\end{array}$ & Desire & Conflict & Resistance & $\begin{array}{l}\text { State self } \\
\text { control } \\
\text { capacity }\end{array}$ & $\begin{array}{l}\text { Trait self } \\
\text { control } \\
\text { capacity }\end{array}$ & Desire & Conflict & Resistance \\
\hline & $\begin{array}{l}\text { Dependant } \\
\text { variables }\end{array}$ & & & & & & & & & & & \\
\hline & Desire & & - & - & - & - & - & - & $\begin{array}{c}-\mathbf{- 3 2}^{*} \\
{[-.56 ;-.09]}\end{array}$ & - & - & - \\
\hline$\frac{\bar{\theta}}{8}$ & Conflict & & - & $\begin{array}{c}-. .06 \\
{[-.13 ;-.01]}\end{array}$ & - & - & - & - & $\begin{array}{c}-.52^{* *} \\
{[-.80 ;-.23]}\end{array}$ & $\begin{array}{c}. \mathbf{2 0} \\
{[.03 ; .35]}\end{array}$ & - & - \\
\hline $\begin{array}{l}\Xi \\
\Xi \\
\Xi\end{array}$ & Resistance & & - & $\begin{array}{c}-.20 \\
{[-.34 ;-.09]}\end{array}$ & $\begin{array}{c}. \mathbf{0 8} \\
{[.01 ; .14]}\end{array}$ & - & - & - & $\begin{array}{c}-.20 \\
{[-.34 ;-.09]}\end{array}$ & $\begin{array}{c}. \mathbf{. 8}^{*} \\
{[.01 ; .14]}\end{array}$ & $\begin{array}{c}\mathbf{. 3 9}^{* * *} \\
{[-.75 ;-.06]}\end{array}$ & - \\
\hline $\begin{array}{l}\overline{0} \\
\overline{0} \\
\tilde{D}\end{array}$ & MVPA & & - & - & - & - & - & - & $\begin{array}{c}\mathbf{4 . 4 8}^{*} \\
{[1.20 ; 7.13]}\end{array}$ & - & - & - \\
\hline & $\begin{array}{l}\text { Sedentary } \\
\text { time }\end{array}$ & & - & -.37 & $\begin{array}{c}\mathbf{- . 0 7} \\
{[-.18 ;-.01]} \\
\end{array}$ & $\begin{array}{c}-. .34^{*} \\
{[-.75 ;-.06]}\end{array}$ & - & - & -.37 & $\begin{array}{c}\mathbf{1 . 6 7}^{*} \\
{[.58 ; 3.00]} \\
\end{array}$ & $\begin{array}{c}-. .34^{*} \\
{[-.75 ;-.06]}\end{array}$ & $\begin{array}{c}-.87^{*} \\
{[-1.93 ;-.17]}\end{array}$ \\
\hline & Desire & & - & - & - & - & - & $\begin{array}{c}-\mathbf{- . 2 2} \\
{[-.38 ;-.10]}\end{array}$ & -.20 & - & - & - \\
\hline $\bar{\theta}$ & Conflict & & $\begin{array}{c}-. .04 \\
{[-.10 ;-.01]}\end{array}$ & -.04 & - & - & - & $\begin{array}{c}-. .04 \\
{[-.10 ;-.00]}\end{array}$ & $\begin{array}{c}-.500^{* * *} \\
{[-.78 ;-.20]}\end{array}$ & $\begin{array}{c}.20 \\
{[.03 ; .35]}\end{array}$ & - & - \\
\hline$\frac{\stackrel{̊}{\Xi}}{\text { శ }}$ & Resistance & & $\begin{array}{c}-. .02^{*} \\
{[-.04 ;-.00]}\end{array}$ & $\begin{array}{c}\mathbf{- . 1 9 * *} \\
{[-.33 ;-.08]}\end{array}$ & $\begin{array}{c}. \mathbf{. 8 8}^{*} \\
{[.01 ; .14]}\end{array}$ & - & - & $\begin{array}{c}\mathbf{- . 0 2}^{*} \\
{[-.04 ;-.00]}\end{array}$ & $\begin{array}{c}-.19^{* * *} \\
{[-.33 ;-.08]}\end{array}$ & $\begin{array}{c}\mathbf{. 0 8 * *} \\
{[.01 ; .14]}\end{array}$ & $\begin{array}{c}. \mathbf{3 4}^{* *} \\
{[.26 ; .48]}\end{array}$ & - \\
\hline 江 & MVPA & & - & - & - & - & - & $\begin{array}{c}\mathbf{4 . 7 5}^{* * *} \\
{[2.92 ; 6,88]}\end{array}$ & - & - & - & - \\
\hline & $\begin{array}{l}\text { Sedentary } \\
\text { time }\end{array}$ & & $\begin{array}{c}-.37^{*} \\
{[-.84 ;-.10]}\end{array}$ & -.19 & $\begin{array}{c}-. .07 \\
{[-.18 ;-.01]}\end{array}$ & $\begin{array}{c}-. .34^{*} \\
{[-.75 ;-.06]}\end{array}$ & - & $\begin{array}{c}-.37^{* *} \\
{[-.84 ;-.10]}\end{array}$ & -.19 & $\begin{array}{c}\mathbf{1 . 6 7}^{\mathbf{*}} \\
{[.58 ; 3.00]}\end{array}$ & $\begin{array}{c}-. .34^{*} \\
{[-.75 ;-.06]}\end{array}$ & $\begin{array}{c}-.87^{*} \\
{[-1.93 ;-.17]}\end{array}$ \\
\hline
\end{tabular}


Table 2. Healthy and unhealthy diet models. All coefficients are unstandardized. Significant coefficients are bolded. $* \mathrm{p}<.05, * * \mathrm{p}<.01, * * * \mathrm{p}<.001$. Numbers into brackets represent $95 \%$ confidence intervals.

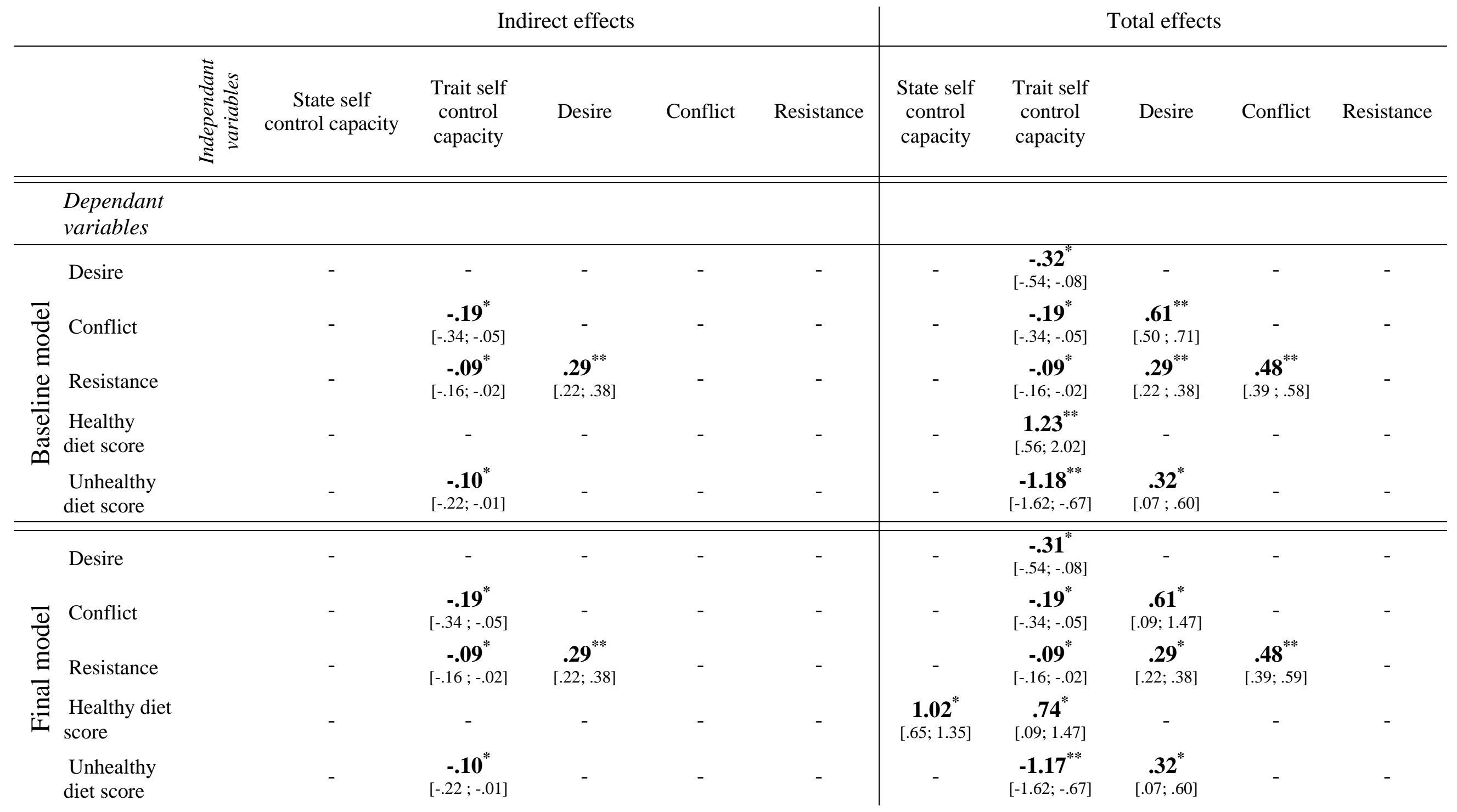


Table 3. Cigarette consumption model. All coefficients are unstandardized. Significant coefficients are bolded. * $\mathrm{p}<.05$, ** $\mathrm{p}<.01$, *** $\mathrm{p}<.001$. Numbers into brackets represent $95 \%$ confidence intervals.

\begin{tabular}{|c|c|c|c|c|c|c|c|c|c|c|c|c|}
\hline & & \multicolumn{6}{|c|}{ Indirect effects } & \multicolumn{5}{|c|}{ Total effects } \\
\hline & & 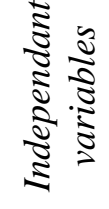 & $\begin{array}{c}\text { State self } \\
\text { control capacity }\end{array}$ & $\begin{array}{l}\text { Trait self } \\
\text { control } \\
\text { capacity }\end{array}$ & Desire & Conflict & Resistance & $\begin{array}{l}\text { State self } \\
\text { control } \\
\text { capacity }\end{array}$ & $\begin{array}{l}\text { Trait self } \\
\text { control } \\
\text { capacity }\end{array}$ & Desire & Conflict & Resistance \\
\hline & $\begin{array}{l}\text { Dependant } \\
\text { variables }\end{array}$ & & & & & & & & & & & \\
\hline \multirow{4}{*}{ 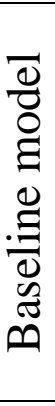 } & Desire & & - & - & - & - & - & - & $\begin{array}{c}\mathbf{- . 8 1} \mathbf{1}^{* * *} \\
{[-1.05 ;-.58]}\end{array}$ & - & - & - \\
\hline & Conflict & & - & $\begin{array}{c}-.39^{* *} \\
{[-.56 ;-.24]}\end{array}$ & - & - & - & - & $\begin{array}{c}\mathbf{- . 3 9} \mathbf{9}^{\text {*** }} \\
{[-.56 ;-.24]}\end{array}$ & $\begin{array}{c}\mathbf{4 9}^{* * *} \\
{[.35 ; .62]}\end{array}$ & - & - \\
\hline & Resistance & & - & $\begin{array}{c}-.20 \\
{[-.31 ;-.12]}\end{array}$ & $\begin{array}{c}. \mathbf{2 5} \\
{[.15 ; .34]}\end{array}$ & - & - & - & $\begin{array}{c}\mathbf{- . 2 0} \\
{[-.31 ;-.12]}\end{array}$ & $\begin{array}{c}. \mathbf{. 5}^{* * *} \\
{[.35 ; .62]}\end{array}$ & $\begin{array}{c}. \mathbf{5 1} \mathbf{1}^{* *} \\
{[.38 ; .64]}\end{array}$ & - \\
\hline & $\begin{array}{l}\text { Number of } \\
\text { cigarettes }\end{array}$ & & - & $\begin{array}{c}\mathbf{- . 8 9} 9^{* * *} \\
{[-1.23 ;-.64]}\end{array}$ & $\begin{array}{c}-. .04 \\
{[-.07 ;-.02]}\end{array}$ & $\begin{array}{c}\mathbf{- . 0 8} * * \\
{[-.13 ;-.04]}\end{array}$ & - & - & $\begin{array}{c}\mathbf{- . 8 9}^{* * *} \\
{[-1.23 ;-.64]}\end{array}$ & $\begin{array}{c}\mathbf{1 . 1 0}^{\text {*** }} \\
{[1.00 ; 1.29]}\end{array}$ & $\begin{array}{c}-.08^{* * *} \\
{[-.13 ;-.04]}\end{array}$ & $\begin{array}{c}-.16 \\
{[-.25 ;-.08]}\end{array}$ \\
\hline \multirow{4}{*}{ 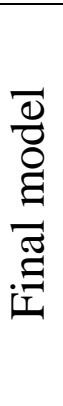 } & Desire & & - & - & - & - & - & - & $\begin{array}{c}\mathbf{- . 8 1} \mathbf{1}^{* * *} \\
{[-1.05 ;-.58]}\end{array}$ & - & - & - \\
\hline & Conflict & & - & $\begin{array}{c}-.41^{* *} \\
{[-.59 ;-.26]}\end{array}$ & - & - & - & $\begin{array}{c}. \mathbf{2 0} \\
{[.01 ; .36]}\end{array}$ & $\begin{array}{c}-. .41^{* *} \\
{[-.59 ;-.24]}\end{array}$ & $\begin{array}{c}.51^{* *} \\
{[.37 ; .64]}\end{array}$ & - & - \\
\hline & Resistance & & $\begin{array}{c}\mathbf{. 1 0}^{*} \\
{[.01 ; .19]}\end{array}$ & $\begin{array}{c}\mathbf{- . 2 1} \mathbf{1}^{* * *} \\
{[-.32 ;-.13]}\end{array}$ & $\begin{array}{c}. \mathbf{2 6} \\
{[.16 ;} \\
\text { **36] }\end{array}$ & - & - & $\begin{array}{c}. \mathbf{1 0}^{*} \\
{[.01 ; .19]}\end{array}$ & $\begin{array}{c}-.21^{* * *} \\
{[-.32 ;-.13]}\end{array}$ & $\begin{array}{c}. \mathbf{2 6} \\
{[.16 ;} \\
\text { ***36] }\end{array}$ & $\begin{array}{c}. \mathbf{5 1}^{* * *} \\
{[.38 ; .64]}\end{array}$ & - \\
\hline & $\begin{array}{l}\text { Number of } \\
\text { cigarettes }\end{array}$ & & $\begin{array}{c}-. .02^{*} \\
{[-.04 ;-.00]}\end{array}$ & $\begin{array}{c}-.89^{* * *} \\
{[-1.23 ;-.64]}\end{array}$ & $\begin{array}{c}-. .04 \\
{[-.08 ;-.02]}\end{array}$ & $\begin{array}{c}-. .08 \text { *** } \\
{[-.13 ;-.04]}\end{array}$ & - & $\begin{array}{c}-. .02 * \\
{[-.04 ;-.01]}\end{array}$ & $\begin{array}{c}\mathbf{- . 8 9} \\
{[-1.23 ;-.63]}\end{array}$ & $\begin{array}{c}\mathbf{1 . 1 0}^{\text {**** }} \\
{[1.00 ; 1.29]}\end{array}$ & $\begin{array}{c}\mathbf{- . 0 8}^{* * *} \\
{[-.13 ;-.04]}\end{array}$ & $\begin{array}{c}\mathbf{- . 1 6}{ }^{* * *} \\
{[-.25 ;-.08]}\end{array}$ \\
\hline
\end{tabular}

